\title{
Mixed mating system and variable mating patterns in tropical woody bamboos
}

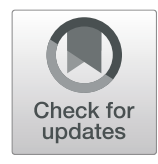

Ning Xie ${ }^{1,2+}$, Ling-Na Chen ${ }^{1 \dagger}$, Yu-Ran Dong ${ }^{1}$ and Han-Qi Yang ${ }^{1 *}$ (D)

\begin{abstract}
Background: So far, little is known in detail about mating systems of woody bamboos. Paternity analysis of offspring improved our understanding of these systems, and contributed to their germplasm conservation and genetic improvement.

Results: In this study, a paternity analysis of offspring from two consecutive mass or sporadically flowering events of Dendrocalamus membranaceus and D. sinicus were conducted to determine their mating system and pollen dispersal using the program COLONY based on simple sequence repeat (SSR) markers. Two sporadically flowering populations of $D$. sinicus $(C 1, C 2)$ obtained relatively high paternity assignments rates (69.0-71.4\%). Meanwhile, among three populations of $D$. membranaceus, the sporadically flowering population $A$ also had much higher paternity assignments rates (56.4\%) than mass flowering populations B1(28.6\%) and B2 (42.5\%). Both D. membranaceus and $D$. sinicus had mixed mating systems while their mating patterns were variable depending on pollination conditions. The maximum pollen dispersal distances were $90 \mathrm{~m}$ and $4378 \mathrm{~m}$ for $D$. membranaceus and $D$. sinicus populations, respectively, and the mating distances of these two species focused on ranges of ca. 0-50 m and $0-1500 \mathrm{~m}$, respectively.

Conclusions: These results revealed for the first time variable mating patterns in woody bamboos. This suggests half-sib seeds from the same bamboo clump may have different male parents and it is crucial to clarify genetic origin in woody bamboos' breeding programs. The results also indicate the importance of pollinators in the mating systems of tropical woody bamboos.
\end{abstract}

Keywords: Dendrocalamus, Mating system, Paternity analysis, Pollen dispersal, Woody bamboo

\section{Background}

Mating systems are generally defined as the mating patterns among individuals, mainly referring to selfing or outcrossing rates and gene flow [1-4]. Mating systems are the crucial part of plant breeding systems that control genetic exchange and play a key role in determining the genetic structure of plant populations, and have a profound influence on survival and evolution of plant species $[2,4,5]$. Meanwhile, background knowledge of mating systems helps us to develop genetic improvement strategies and establish appropriate conservation measures [6].

\footnotetext{
* Correspondence: yanghanqikm@aliyun.com

${ }^{\dagger}$ Ning Xie and Ling-Na Chen contributed equally to this work.

${ }^{1}$ Research Institute of Resources Insects, Chinese Academy of Forestry,

Bailongsi, Panlong District, Kunming 650233, China

Full list of author information is available at the end of the article
}

Woody bamboos (Poaceae: Bambusoideae) comprise ca. Eighty genera including more than 1200 species, which are mainly distributed in the subtropical and tropical regions of Asia, America and Africa [7, 8]. Woody bamboos are shrub forest species which have important economic value such as food, construction and pulp materials, as well as important roles in water and soil conservation $[9,10]$. One of the most compelling biological properties of woody bamboos concerns their unusual flowering phenology [11-14]. There are two common unofficial terms related to flowering and mating systems of bamboos. Firstly, based on origin of woody bamboo forests, bamboo species can generally be divided into wild and cultivated species [12]. Secondly, in terms of the size of flowering forests or populations, woody bamboo flowering events can be divided on the whole into two types, namely mass and sporadic flowering $[11,15,16]$. Due to outstandingly long vegetative growth periods (ca. 20-150 years)

(c) The Author(s). 2019 Open Access This article is distributed under the terms of the Creative Commons Attribution 4.0 International License (http://creativecommons.org/licenses/by/4.0/), which permits unrestricted use, distribution, and 
among seed plant and uncertainty of flowering events [11], so far, little is known about the mating systems of most bamboo species [7, 10, 15], which greatly hinders studies on their germplasm conservation and genetic improvement [9].

As for characteristics of mating systems, most of the documented woody bamboos were dichogamous and protogynous, and were generally considered to be windpollinated species [11, 16-18]. However, it is still in controversy about whether bamboos are obligate outcrossers [16]. Within tropical bamboos, Dendrocalamus spp. demonstrated a breeding system suitable for hybridization [16-18]. Recently, paternity analyses of several wild temperate woody bamboo species, such as Sasa cernua (sporadicflowering, [19]), S. veitchii var. hirsuta (mass-flowering, [20]) and Phyllostachys edulis (sporadic-flowering, [21]) were reported. All of those studies were based on results from single bamboo flowering events, and it seemed that studied species were self-compatible. Meanwhile, it appeared that selfing was predominant in sporadic flowering events while outcrossing was predominant in mass flowering events.

As one of the regions with the most woody bamboo species in the world, Yunnan Province of China possesses more than 230 native species from 28 genera [10]. From 2008 to 2015, many bamboos experienced mass and sporadically flowering following a prolonged severe drought in Yunnan [22, 23]. In particular, the mass and sporadic flowering of Dendrocalamus membranaceus and sporadic flowering of $D$. sinicus were often observed [16, 22, 23] (Fig. 1). This provided a good opportunity for us to investigate the characteristics of bamboo mating systems.

Dendrocalamus membranaceus is mainly distributed in middle and lower Lancang-Mekong River valley including Myanmar, Laos, Thailand and China's Yunnan Province, with an elevation range of 500-1000 m [24]. In Yunnan, D. membranaceus often grows into large-scale natural forests, totally covering a region of ca. 30,000 $\mathrm{hm}^{2}$ in 2008 , and is the largest natural bamboo forest in China [24]. This species is economically important as vegetable crops and raw materials for furniture, construction and industrial paper pulp [7]. Dendrocalamus sinicus is endemic to southwestern Yunnan at elevations of $500-1800 \mathrm{~m}$, and is famous for its strongest culms among woody bamboos in the world so that it is an important bamboo species for producing timber [10]. Dendrocalamus sinicus is cultivated by local Wa or Dai peoples in Yunnan.

In our previous study about pollination and breeding systems in wild $D$. membranaceus populations and cultivated $D$. sinicus population based on morphology observation and hand pollination experiment, we inferred that both were self-compatible and predominantly outcrossing [16]. Here, we investigated the mating systems of mass or sporadic flowering populations of these two typical tropical woody bamboos, i.e., wild $D$. membranaceus and cultivated $D$. sinicus, based on data from two continuous flowering events and using simple sequence repeat (SSR) molecular markers. We carried out paternity analyses using program COLONY [25], and estimated selfing and outcrossing rates, male reproductive fitness,
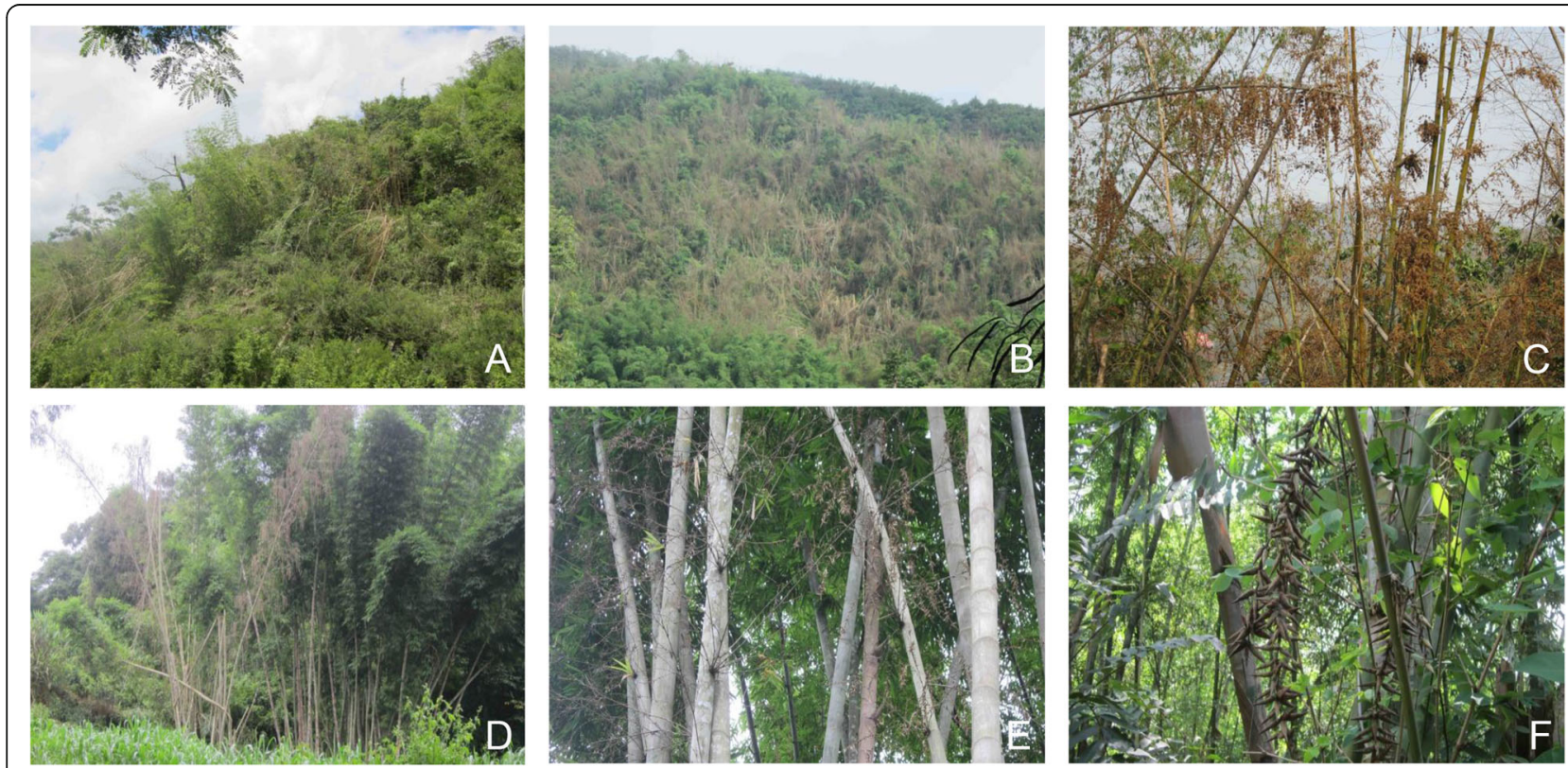

Fig. 1 Sporadically flowering (photo a, site A), mass flowering (photo b, site B) populations and flowering clumps (photo c) of D. membranaceus, and sporadically flowering population of $D$. sinicus (photos $\mathbf{d}-\mathbf{f}$, site $C$ ) in southwestern Yunnan, China 
and pollen dispersal in mass and sporadic flowering populations of D. membranaceus and sporadic flowering populations of $D$. sinicus. Our goals were to understand the characteristics of the mating systems of tropical woody bamboos so as to provide a scientific foundation for germplasm conservation and further genetic improvement.

\section{Results}

\section{Mating system}

Outcrossing rates of Dendrocalamus membranaceus and D. sinicus were estimated using MLTR [5], and the result indicated that both $D$. membranaceus and D. sinicus were predominant outcrossing (Table 1). Multilocus outcrossing rate of mass flowering populations (B1, B2) of D. membranaceus were 1.000 , which was higher than the sporadically flowering population $\mathrm{A}\left(\mathrm{t}_{\mathrm{m}}=0.643\right)$. The single-locus outcrossing rate $\left(t_{\mathrm{s}}\right)$ of population A was highest $\left(t_{s}=0.843\right)$, and population B1 was lowest $\left(t_{s}=\right.$ 0.001 ). On the other hand, biparental inbreeding of population $\mathrm{B} 1\left(\mathrm{t}_{\mathrm{m}}-\mathrm{t}_{\mathrm{s}}=0.999\right)$ was highest among three $D$. membranaceus populations, indicating that individuals within population B1 were close relatives. Meanwhile, population A had the lowest biparental inbreeding $\left(\mathrm{t}_{\mathrm{m}}-\right.$ $\left.t_{s}=-0.200\right)$, indicating an excess of heterozygotes.

Outcrossing rates of sporadically flowering populations $(\mathrm{C} 1, \mathrm{C} 2)$ of D. sinicus were relatively high, and both multilocus and single-locus outcrossing rates of population $\mathrm{C} 1$ were higher than population $\mathrm{C} 2$. The values of biparental inbreeding were very low in populations $\mathrm{C} 1$ and $C 2$, which were 0.042 and -0.027 , respectively. This suggests an excess of heterozygotes within sporadically flowering populations of $D$. sinicus.

\section{Paternity assignments}

Paternity assignments (with 95\% confidence) of Dendrocalamus membranaceus and D. sinicus based on COLONY [25] are given in Table 2, Additional file 1: Table S1 and Additional file 2: Table S2. Low to moderate assignment rates (28.6-56.4\%) were found among $D$. membranaceus populations while considerably higher assignment rates $(69.0-71.4 \%)$ occurred within D. sinicus populations. Among D. membranaceus populations, 57 out of 101 offspring (56.4\%) of population A were successfully assigned to the most likely male parents, and
43 offspring (42.6\%) were inferred as outcrossing, indicating that the mating pattern of population $\mathrm{A}$ is dominated by outcrossing. Within population B1, male parents of 100 out of 350 offspring (28.6\%) were assigned, and $78(22.3 \%)$ offspring were from outcrossing. Among the 240 offspring of population B2, 102 (42.5\%) were successfully assigned to their male parents, including 56 selfing offspring and 46 outcrossing offspring, suggesting that selfing may be the main mating pattern within this population.

For D. sinicus populations, 87 offspring (69.0\%) in population $\mathrm{C} 1$ and 95 offspring (71.4\%) in population $\mathrm{C} 2$ were assigned to their male parents (Table 2). Of them, $62.7 \%$ offspring of population $\mathrm{C} 1$ were identified as selfing while only $20.3 \%$ offspring were identified as selfing and $51.1 \%$ as outcrossing in population $\mathrm{C} 2$, indicating that different mating patterns occurred within sporadically flowering populations of $D$. sinicus.

\section{Pollen dispersal distance and male reproductive contribution}

We analyzed the male reproductive contribution of every flowering clump within five populations based on the result of paternity assignment (Table 3 ). Within population $\mathrm{A}$, the maximum reproductive contribution was from clump A4 (42.1\%), which produced 24 offspring. For population B1, both clumps FU4 and B2 produced 10 offspring, and had the maximum reproductive contribution (16.4\%). Within population B2, clump C5 produced 53 offspring and had the maximum reproductive contribution (52.0\%). For D. sinicus populations, the candidate male parent clump 13 in population $\mathrm{C} 1$ had a maximum reproductive contribution $(73.6 \%)$ and produced 64 selfing offspring. Within population $\mathrm{C} 2$, clump 13B produced 66 offspring, and had reproductive contribution of $69.5 \%$.

According to the results of paternity analysis, we found that the maximum mating distance for sporadic and mass flowering populations of $D$. membranaceus were $72 \mathrm{~m}$ and $90 \mathrm{~m}$, respectively. On the other hand, $D$. sinicus has a much longer mating distance $(4378 \mathrm{~m}$, Table 3). For sporadic flowering populations of $D$. membranaceus and D. sinicus, the mating distance was mainly concentrated on $0 \mathrm{~m}$, indicating that most offspring were self-pollinated or geitonogamous. For mass

Table 1 Estimation of outcrossing rates of D. membranaceus and D. sinicus based on MLTR

\begin{tabular}{lllll}
\hline Species & Population & Multilocus outcrossing rate $\left(\mathrm{t}_{\mathrm{m}}\right)$ & Single-locus outcrossing rate $\left(\mathrm{t}_{\mathrm{s}}\right)$ & Biparental inbreeding $\left(\mathrm{t}_{\mathrm{m}}-\mathrm{t}_{\mathrm{s}}\right)$ \\
\hline D. membranaceus & A & 0.643 & 0.843 & -0.200 \\
& B1 & 1.000 & 0.001 & 0.999 \\
& B2 & 1.000 & 0.804 & 0.196 \\
D. sinicus & C1 & 1.200 & 1.158 & 0.042 \\
& C2 & 0.697 & 0.724 & -0.027 \\
\hline
\end{tabular}


Table 2 Paternity assignments using COLONY

\begin{tabular}{|c|c|c|c|c|c|c|c|c|}
\hline \multirow[t]{2}{*}{ Species } & \multirow[t]{2}{*}{ Population } & \multirow{2}{*}{$\begin{array}{l}\text { Total } \\
\text { offspring }\end{array}$} & \multirow{2}{*}{$\begin{array}{l}\text { Assigned } \\
\text { offspring }\end{array}$} & \multirow{2}{*}{$\begin{array}{l}\text { Assignment } \\
\text { rate (\%) }\end{array}$} & \multicolumn{2}{|l|}{ Selfing } & \multicolumn{2}{|c|}{ Outcrossing } \\
\hline & & & & & Amount & Percentage of total (\%) & Amount & Percentage of total (\%) \\
\hline \multirow[t]{3}{*}{ D. membranaceus } & A & 101 & 57 & 56.4 & 14 & 13.9 & 43 & 42.6 \\
\hline & $\mathrm{B} 1$ & 350 & 100 & 28.6 & 22 & 6.3 & 78 & 22.3 \\
\hline & B2 & 240 & 102 & 42.5 & 56 & 23.3 & 46 & 19.2 \\
\hline \multirow[t]{2}{*}{ D. sinicus } & $\mathrm{C} 1$ & 126 & 87 & 69.0 & 79 & 62.7 & 8 & 6.3 \\
\hline & $\mathrm{C} 2$ & 133 & 95 & 71.4 & 27 & 20.3 & 68 & 51.1 \\
\hline
\end{tabular}

Table 3 Male reproductive contribution and pollen dispersal distance of D. membranaceus and D. sinicus

\begin{tabular}{|c|c|c|c|c|c|c|}
\hline Species & Population & Candidate male parent & Female parent & Amount of offspring & $\begin{array}{l}\text { Male reproductive } \\
\text { contribution (\%) }\end{array}$ & $\begin{array}{l}\text { Pollen dispersal } \\
\text { distance }(\mathrm{m})\end{array}$ \\
\hline \multirow[t]{24}{*}{ D. membranaceus } & \multirow[t]{8}{*}{$A$} & A0 & $A 5, A 6$ & 4 & 7.0 & 60,72 \\
\hline & & A1 & $\mathrm{A} 4, \mathrm{~A} 6$ & 5 & 8.8 & 39,61 \\
\hline & & $\mathrm{A} 2$ & $\mathrm{~A} 3, \mathrm{~A} 4, \mathrm{~A} 5, \mathrm{~A} 6$ & 15 & 26.3 & $16,28,39,50$ \\
\hline & & A3 & $\mathrm{A} 2, \mathrm{~A} 4, \mathrm{~A} 5$ & 5 & 8.8 & $16,12,23$ \\
\hline & & A4 & $\mathrm{A} 2, \mathrm{~A} 3, \mathrm{~A} 4, \mathrm{~A} 5$ & 24 & 42.1 & $28,12,0,11$ \\
\hline & & A5 & $\mathrm{A} 4, \mathrm{~A} 5, \mathrm{~A} 6$ & 4 & 7.0 & $11,0,11$ \\
\hline & & A6 & - & - & - & - \\
\hline & & A7 & - & - & - & - \\
\hline & \multirow[t]{11}{*}{ B1 } & FU1 & B5, B6, & 2 & 3.3 & 44,34 \\
\hline & & FU2 & B4, B7 & 3 & 4.9 & 27,88 \\
\hline & & FU3 & $\mathrm{B} 1, \mathrm{~B} 2, \mathrm{~B} 4, \mathrm{~B} 5, \mathrm{~B} 6$ & 7 & 11.5 & $45,43,8,11,74$ \\
\hline & & FU4 & $\mathrm{B} 1, \mathrm{~B} 2, \mathrm{~B} 3, \mathrm{~B} 4, \mathrm{~B} 6, \mathrm{~B} 7$ & 10 & 16.4 & $49,54,52,72,34,37$ \\
\hline & & B1 & B2, B4, B6 & 4 & 6.6 & $5,37,31$ \\
\hline & & B2 & $B 1, B 2$ & 10 & 16.4 & 5,0 \\
\hline & & B3 & B1, B4, B6, B7 & 5 & 8.2 & $6,41,30,55$ \\
\hline & & B4 & $\mathrm{B} 1, \mathrm{~B} 2, \mathrm{~B} 3, \mathrm{~B} 6, \mathrm{~B} 7$ & 7 & 11.5 & $37,36,41,66,90$ \\
\hline & & B5 & B3, B5, B7 & 5 & 8.2 & $43,0,89$ \\
\hline & & B6 & B3, B7 & 2 & 3.3 & 30,25 \\
\hline & & B7 & B1, B2, B3, B4, B6, B7 & 6 & 9.8 & $56,60,55,90,25,0$ \\
\hline & \multirow[t]{5}{*}{ B2 } & C1 & $\mathrm{C} 1, \mathrm{C} 4, \mathrm{C} 5$ & 22 & 21.6 & $0,23,36$ \\
\hline & & C2 & $\mathrm{C} 1, \mathrm{C} 2, \mathrm{C} 3$ & 15 & 14.7 & $12,0,13$ \\
\hline & & C3 & $C 2, C 3$ & 2 & 2.0 & 13,0 \\
\hline & & C4 & $\mathrm{C} 2, \mathrm{C} 3, \mathrm{C} 4, \mathrm{C} 5$ & 10 & 9.8 & $10,8,0,16$ \\
\hline & & C5 & $\mathrm{C} 1, \mathrm{C} 3, \mathrm{C} 4, \mathrm{C} 5$ & 53 & 52.0 & $36,15,26,0$ \\
\hline \multirow[t]{8}{*}{ D. sinicus } & \multirow[t]{4}{*}{$\mathrm{C} 1$} & 6 & 6,13 & 23 & 26.4 & 0,4378 \\
\hline & & 13 & 13 & 64 & 73.6 & 0 \\
\hline & & $5 \mathrm{~A}$ & - & - & - & - \\
\hline & & $5 B$ & - & - & - & - \\
\hline & \multirow[t]{4}{*}{$\mathrm{C} 2$} & 2 & 2 & 1 & 1.1 & 0 \\
\hline & & 3 & $2,3,13 \mathrm{~B}$ & 26 & 27.4 & $1113,0,1736$ \\
\hline & & $13 \mathrm{~A}$ & 2 & 2 & 2.1 & 3338 \\
\hline & & $13 B$ & $3,13 \mathrm{~A}, 13 \mathrm{~B}$ & 66 & 69.5 & $1736,1458,0$ \\
\hline
\end{tabular}


flowering populations of $D$. membranaceus, the mating distance focused on a range of $0-50 \mathrm{~m}$. Over $50 \mathrm{~m}$, the amount of offspring reduced significantly with increasing geographical distance (Fig. 2).

Moreover, we did not find that candidate male parents preferred specific female parents to produce more offspring in D. membranaceus populations, while in sporadically flowering populations of $D$. sinicus, it appears that females tended to accept pollen from the closest males. For example, clumps 13A (female) and 13B (male) produced 43 outcrossing offspring, accounting for $63.2 \%$ of total outcrossing offspring in population C2 (Table 3, Additional file 2: Table S2).

\section{Discussion}

\section{Mating system and variable mating patterns}

Plant mating system is influenced by many factors, such as population density, floral synchronism, and post-pollination mechanisms [26]. In general, predominant selfing is common mating pattern within sporadically flowering populations of woody bamboos [18, 19, 21, 27], while predominant outcrossing is common in mass flowering populations [20]. In this study, a variable mating pattern of two tropical bamboo species was detected based on data from two consecutive flowering events over 2 years.

In a previous study, we inferred that both $D$. membranaceus and $D$. sinicus had mixed mating systems with predominant outcrossing [16]. In the present study, we confirmed they were self-compatible. However their mating patterns changed depending on different flowering situations or pollination conditions. Predominant outcrossing was detected in both sporadic (population A in 2013) and mass (population B1 in 2013) flowering populations of $D$. membranaceus, while predominant selfing occurred in mass flowering population B2 in 2014. Similarly, sporadically flowering populations of $D$.

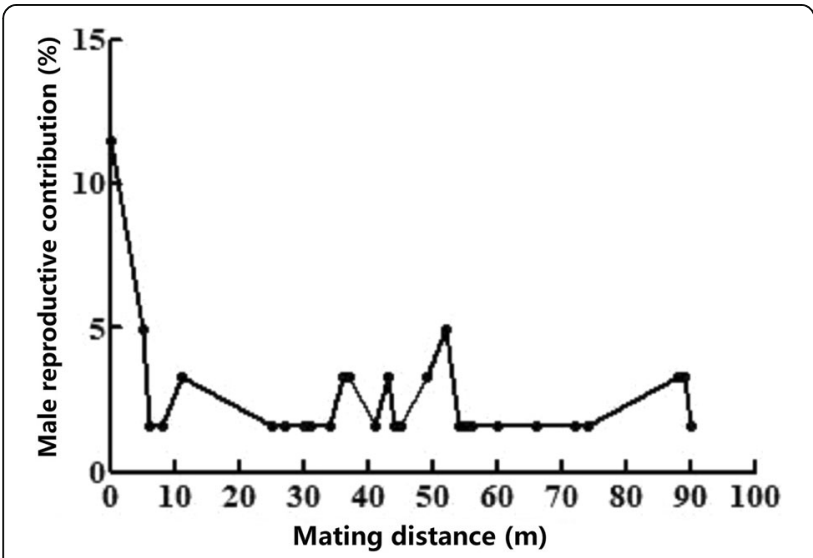

Fig. 2 Relationships between male reproductive contribution and mating distance within flowering populations of D. membranaceus sinicus demonstrated a mating pattern of predominant selfing in 2013 (population C1) and predominant outcrossing in 2015 (population C2).

The above observations might be associated with the flowering clump (or pollen) densities and foraging behavior of pollinator (e.g. honeybees) of bamboo populations [16, 22, 23]. Woody bamboos are generally considered to be wind-pollinated, and some studies have demonstrated that Dendrocalamus spp. are dichogamous and protogynous [16-18, 27]. A long flowering period (ca. one to 2 months) of $D$. membranaceus and D. sinicus allows the possibility of geitonogamous pollination within and among ramets [16, 21]. Mass flowering populations would provide greater pollen density than sporadically flowering populations. On the other hand, honeybees appeared to be good pollinators for $D$. membranaceus and $D$. sinicus [16]. Frequently clear and dry weather in 2013 is conducive for honeybees to pollinate. Therefore, populations A and B1 of D. membranaceus showed a mating pattern of predominant outcrossing. By comparison, commonly rainy weather during flowering period of D. membranaceus in 2014 hindered windpollination and honeybee pollination, thus decreased the outcrossing rate of population B2. As for D. sinicus, most seeds in 2015 (population C2) were from flowering clumps within less than $1800 \mathrm{~m}$ (Table 3), which was much shorter than interval distances of flowering clumps in 2013 (population C1). Short distances are beneficial to honeybees, and correspondingly increased the opportunity for outcrossing in population $\mathrm{C} 2$ more than in population $\mathrm{C} 1$ [28].

For breeding programs of woody bamboos, particularly programs based on seeds, the variable mating patterns will vastly increase the complexity of paternal genetic origin. This suggests that the first step in the breeding or selection of new bamboo varieties is to clarify genetic origin of the parents.

\section{Difference of paternity assignments rates between $D$. membranaceus and $D$. sinicus}

Two sporadically flowering populations of $D$. sinicus (C1, C2) obtained relatively high paternity assignments rates $(69.0-71.4 \%)$. Meanwhile, among three populations of D. membranaceus, the sporadically flowering population A also had much higher paternity assignments rates (56.4\%) than mass flowering populations B1 (28.6\%) and B2 (42.5\%) (Table 2). Therefore, it was obvious that sporadically flowering populations $(\mathrm{A}, \mathrm{C} 1, \mathrm{C} 2)$ also displayed much higher paternity assignments rates than mass flowering populations (B1, B2). One of main reasons accounting for low assignment rates in mass flowering populations of $D$. membranaceus in the present study was integrity of the candidate male parents. Although we did not find other flowering clumps of $D$. 
membranaceus within the range of $200 \mathrm{~m}$ around populations A, B1 and B2 from 2012 to 2015, it was possible that honeybees frequently visited the fresh florets [16] and carried exogenous pollen into populations and resulted into a low assignment rates (28.6-56.4\%). Compared with $D$. membranaceus, $D$. sinicus had usually rarer events of flowering and seeding. From 2013 to 2016, we did not observe other flowering clumps of $D$. sinicus within the range of ca. 10,000 $\mathrm{m}$ around populations $\mathrm{C} 1$ and $\mathrm{C} 2$. We thus probably collected all candidate male parents in populations $\mathrm{C} 1$ and $\mathrm{C} 2$, and obtained much higher assignment rates (69.0-71.4\%).

Actually, low assignment rates in parentage analysis of natural populations in nature are common [29-31]. Similarly, within plant populations, high proportions of unassigned offspring are usually reported when there is large input from external pollen sources, particularly for wind-pollinated trees [32-35]. Therefore, the missing data of male parents and molecular markers with low resolution were two main reasons for low assignment rates [36-39]. Moreover, it was noteworthy that materials for paternity analysis in the present study came from seedlings of half-sib seeds. The seed germination rates of $D$. membranaceus and $D$. sinicus were only ca. $50-80 \%$ [40]. Thus, it would have a certain extent impact on the results of paternity analysis. The weak seeds or seedlings, particularly for selfing offspring, were excluded from paternity analysis, thus outcrossing rates would be artificially enlarged [19].

\section{Pollen dispersal distance}

There was significant difference in pollen dispersal distance between $D$. sinicus and D. membranaceus. Dendrocalamus sinicus demonstrated a much greater pollen dispersal distance $(4378 \mathrm{~m})$ than D. membranaceus $(90$ $\mathrm{m})$. Meanwhile, different from the viewpoint of Whitehead [41] that probability of mating success rate decreased with the increase of distance between female and male parents, optimum mating distances of D. membranaceus and $D$. sinicus mainly focused on a range of ca. $0-50 \mathrm{~m}$ and $0-1500 \mathrm{~m}$ respectively, with high male reproductive fitness.

Pollen dispersal distance is influenced by multiple factors, such as pollen amount, pollen viability, pollinator activity, weather and so on $[16,42]$. Our results, in conjunction with previous studies, indicated that pollen amount and pollinator activity may be two of the most important factors for pollen dispersal distance and male reproductive fitness of $D$. membranaceus and $D$. sinicus.

The in vitro pollen of D. membranaceus and D. sinicus still had 38.1 and $4.8 \%$ germination ability respectively after being separated from flower branches for 3 hours (Yang et al. unpublished data), so that visiting flowers of honeybees could improve pollen dispersal distance and enhance pollination rates of geitonogamy and xenogamy [16]. However, bees generally had short flight ranges, so pollen movement in populations was biased towards nearby individuals [28]. Moreover, mass flowering or pollen limitation may also cause a short pollen dispersal to improve pollination [42-45].

In our previous studies, we found that $D$. membranaceus populations have denser flowering clumps and produced much more abundant pollen than those of $D$. sinicus, and pollination limitation in $D$. sinicus was more serious than that in D. membranaceus [16]. Therefore, these attributes may result in much shorter pollen dispersal in D. membranaceus populations. On the other hand, although $D$. sinicus demonstrated much farther pollen dispersal distance and optimum mating distance than D. membranaceus, it may be better reflected that interval distance between flowering clumps of $D$. sinicus were much farther away than those of $D$. membranaceus. As a whole, the total selfing rate of D. sinicus (40.9\%) was much higher than that of D. membranaceus (13.3\%, Table 2). When exogenous pollen is insufficient, selfpollination can improve the seed setting rate to ensure the survival of a species, that is, reproductive assurance effect $[1,4,46]$.

\section{Conclusions}

Dendrocalamus membranaceus and D. sinicus demonstrated mixed mating systems and their mating patterns changed depending on pollination conditions. Dendrocalamus sinicus had a much greater pollen dispersal distance than $D$. membranaceus. The mating distances of $D$. membranaceus and $D$. sinicus focused on a range of ca. $0-50 \mathrm{~m}$ and $0-1500 \mathrm{~m}$ respectively. These results also revealed the importance of pollinators, such as honeybees, in the mating systems of tropical woody bamboos.

\section{Materials and methods \\ Study sites and seeds collection}

The flowering populations of Dendrocalamus membranaceus studied in this paper occur in the Xiaomengyang National Nature Reserve (XNNR), Jinghong, Yunnan Province, China (Fig. 3). Mass and sporadic flowering of D. membranaceus occurred from 2011 to 2015 [23]. In 2013, we selected two fixed sites (i.e., A and B) for observation and seed collection (Table 4). Site A (sporadically flowering) was a bamboo-tree mixed forest (bamboo: tree $=9: 1$ ), and the area of quadrat was $10 \times$ $100 \mathrm{~m}^{2}$. Eight flowering clumps were scattered among 55 total clumps (population A). The flowering clumps were not adjacent to each other and distances between flowering clumps were $16-72 \mathrm{~m}$. Site B was in a pure D. membranaceus forest, and the area of quadrat was $40 \times 100$ $\mathrm{m}^{2}$. We found a small population in which all 12 clumps were flowering in 2013 and 2014, and treated it as a 


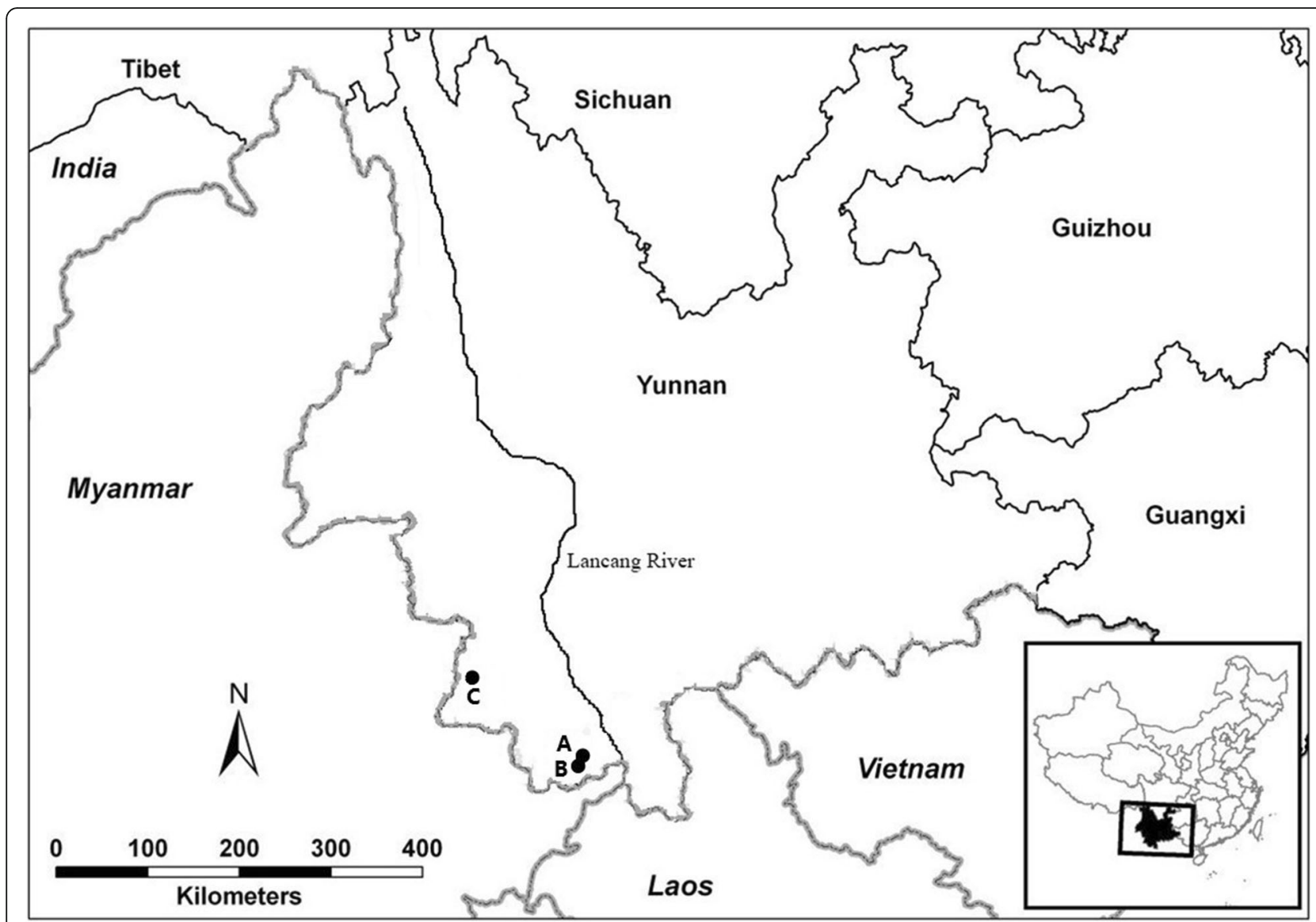

Fig. 3 Location of study sites of D. membranaceus (sites A and B) and D. sinicus (site C) in Yunnan Province, China. Maps were drawn using the sofware ArcGIS version 10.2 (http://desktop.arcgis.com) and modified using Photoshop (Adobe Corporation, California, America)

sample of mass flowering. No other flowering clumps were observed within a range of $200 \mathrm{~m}$ around this quadrat from 2012 to 2015 . In July 2013 there were seven adjacent clumps (population B1) flowering in this quadrat, and the remaining five adjacent clumps (population B2) flowered in July 2014 (Table 4). The flowering periods of populations B1 and B2 did not overlapped.

The sporadically flowering clumps of $D$. sinicus were situated at the Wolong, Ximeng County, Yunnan Province (Fig. 3). In November 2012, four sporadically flowering clumps (population $\mathrm{C} 1$ ) were observed and seeds were collected in June 2013. At almost the same site, another four clumps (population C2) started flowering in January 2015.

The seeds of every population (A, B1, B2, C1 and C2) were collected from the flowering clumps in quadrats at XNNR or Wolong, and then marked with serial numbers (Tables 3 and 4). The voucher specimens of the flowering clumps were identified by Dr. Han-Qi Yang, and were deposited in the herbariums of the Research Institute of Resources Insects, Chinese Academy of Forestry (Kunming, China).

Table 4 Study sites of paternity analyses for D. membranaceus and D. sinicus

\begin{tabular}{|c|c|c|c|c|c|c|c|c|c|}
\hline Species & $\begin{array}{l}\text { Study } \\
\text { site }\end{array}$ & $\begin{array}{l}\text { Longitude } \\
\text { (E) }\end{array}$ & $\begin{array}{l}\text { Latitude } \\
(\mathrm{N})\end{array}$ & $\begin{array}{l}\text { Elevation } \\
(\mathrm{m})\end{array}$ & $\begin{array}{l}\text { sampling } \\
\text { date }\end{array}$ & $\begin{array}{l}\text { Flowering } \\
\text { type }\end{array}$ & $\begin{array}{l}\text { Fruiting } \\
\text { clumps }\end{array}$ & Offsprings & $\begin{array}{l}\text { Candidate } \\
\text { parent }\end{array}$ \\
\hline \multirow{3}{*}{$\begin{array}{l}\text { D. } \\
\text { membranaceus }\end{array}$} & A & $100^{\circ} 52^{\prime} 32^{\prime \prime}$ & $22^{\circ} 09^{\prime} 50^{\prime \prime}$ & 810.0 & 2013.7 & sporadic & 6 & 101 & 8 \\
\hline & B1 & $100^{\circ} 52^{\prime} 27^{\prime \prime}$ & $22^{\circ} 01^{\prime} 51^{\prime \prime}$ & 756.8 & 2013.7 & mass & 7 & 350 & 11 \\
\hline & B2 & $100^{\circ} 52^{\prime} 27^{\prime \prime}$ & $22^{\circ} 01^{\prime} 51^{\prime \prime}$ & 756.8 & 2014.7 & mass & 5 & 240 & 5 \\
\hline \multirow[t]{2}{*}{ D. sinicus } & C1 & $99^{\circ} 31^{\prime \prime} 36^{\prime \prime}$ & $22^{\circ} 43^{\prime} 44^{\prime \prime}$ & 1202.5 & 2013.6 & sporadic & 4 & 126 & 4 \\
\hline & $C 2$ & $99^{\circ} 31^{\prime} 33^{\prime \prime}$ & $22^{\circ} 43^{\prime} 48^{\prime \prime}$ & 1295.0 & 2015.6 & sporadic & 4 & 133 & 4 \\
\hline
\end{tabular}




\section{Seed treatment}

Following McClure [47], we regarded each clump as a potential genet and the culms within as ramets of a clone. Seeds collected from every flowering clump (Table 4) were sown in the greenhouse after treatments [40]. The leaves of seedlings were sampled and dried quickly with silica gel for DNA extractions. Each flowering genet in quadrats was identified as a candidate parent, and their foliage leaves were sampled for DNA extraction.

\section{Microsatellite analysis}

Genomic DNA was extracted using the modified CTAB method [48] and dissolved in TE buffer (10 Mm TrisHCL, pH 8.0, $1 \mathrm{Mm}$ EDTA) to a final concentration of 30-60 ng/L [36]. We used 10 and 11 microsatellite loci (Additional file 3: Table S3) to genotype all the samples of Dendrocalamus membranceus and D. sinicus respectively with the software GeneMarker V. 2.2.0 (SoftGenetics, State College, PA, USA).

PCR amplification was performed according to Dong et al. [37] for D. sinicus and Dong and Yang [36] for D. membranaceus, respectively. PCR reactions were performed in $20 \mathrm{uL}$ volumes, containing 1.0 uL DNA, $10 \mathrm{uL}$ $2 \times$ Taq PCR MasterMix, $8.6 \mathrm{uL} \mathrm{ddH}_{2} \mathrm{O}$ and $0.3 \mathrm{uL}$ of each primer. Fluorescent-labelled primers were mixed with non-fluorescent primers. Cycling conditions included: $95^{\circ} \mathrm{C}$ for $3 \mathrm{~min}$ followed by 34 cycles at $94{ }^{\circ} \mathrm{C}$ for $30 \mathrm{~s}$, with an annealing temperature optimized for each primer pair for $40 \mathrm{~s}, 72^{\circ} \mathrm{C}$ for $50 \mathrm{~s}$, and a final extension step at $72{ }^{\circ} \mathrm{C}$ for $6 \mathrm{~min}$. PCR products were visualized by silver staining on $6 \%$ polyacrylamide denaturing gels with a 20-bp molecular size standard ladder (Tiangen, Beijing, China).

\section{Mating system analysis}

The program MLTR v3.2 [5] was used to assess the mating system from progeny arrays, which is based on maximumlikelihood. The following mating system parameters were estimated by the Newton-Raphson algorithm: multilocus outcrossing rate $\left(t_{m}\right)$, single-locus outcrossing rate $\left(t_{s}\right)$, and Biparental inbreeding $\left(t_{m}-t_{s}\right)$. Standard deviation of these parameters was evaluated from 1000 bootstraps.

\section{Paternity analysis}

We used the program COLONY 2.0 [25] to implement a paternity analysis for offspring of the sporadic and mass flowering populations. Error rate simulation was conducted several times until its value did not change. We performed three replicate runs and each run was performed with a different random number seed. The following parameters were adopted: monoecious species, allowing inbreeding, diploid, polygamy for males and females, full-likelihood method, medium length run, medium precision and no updating allele frequencies. We accepted the assignment for both paternity and maternity if results met one of the following criteria according to Harrison [49]: (1) all three runs were assigned to the same parent with a probability of 95\% or more; (2) assigned to the same parent three times, and two of runs assigned above 95\%; (3) two runs assigned the same parent, both above $95 \%$, but another one runs failed to assign any candidate parent. Assignments were regarded as failed when the most likely male parents were in conflict among results of three replicate runs.

\section{Pollen dispersal and male reproductive success}

Pollen dispersal was carried out for the sporadic and mass flowering populations based on paternity analysis. We deemed all female parent clumps (clumps with seed setting) as candidate male parent clumps in the studied populations, so the pollen dispersal distances were counted according to the geographical distances between female parent clump and inferred male parent clump based on results of paternity analysis. Male reproductive success $(\lambda)$ was calculated by using the equation:

$$
\lambda_{\mathrm{k}}=\mathrm{N}_{\mathrm{k}} / \mathrm{N}, \Sigma \lambda_{\mathrm{k}}=1, \text { for } \mathrm{K}=1,2, \ldots, \mathrm{K}
$$

Where $\mathrm{K}$ is the number of candidate male parent, $\mathrm{N}_{\mathrm{k}}$ is the number of offspring with known female parents and inferred male parent, and $\mathrm{N}$ is the total number of offspring [50, 51]. We also calculated the relationship between mating distance and male reproductive success.

\section{Supplementary information}

Supplementary information accompanies this paper at https://doi.org/10 1186/s12870-019-2024-3.

Additional file 1: Table S1. Paternity analysis of D. membranceus using COLONY.

Additional file 2: Table S2. Paternity analysis of $D$. sinicus using COLONY.

Additional file 3: Table S3. The SSR primers were used for paternity analysis of D. membranceus and D. sinicus.

\section{Acknowledgments}

We thank two anonymous reviewers and Dr. Jian-Jun Gao (Yunnan University) for constructive suggestions that helped to improve this paper.

Authors' contributions

NX and LC were responsible for the management of the seedlings, performed SSR genotyping, analyzed all data; YD contributed to the experiment design and data analysis; NX, LC and HY drafted the manuscript; HY conceived the study, contributed to its design, and critically revised the manuscript. All authors read and approved the final manuscript.

\section{Funding}

This research was funded by the Fundamental Research Funds of the Chinese Academy of Forestry, CAF (CAFYBB2017ZX001-8), the National Natural Science Foundation of China (31870574, 31270662), and Department of Sciences and Technology of Xizang Autonomous Region (XZ201801-GA11). Funding bodies were not involved in the design of the study and collection, analysis, interpretation of data and in writing the manuscript. 


\section{Availability of data and materials}

All data generated or analyzed during this study are included in this published article (and its additional files).

\section{Ethics approval and consent to participate}

The permission for each location was issued by Jinghong Forestry Bureau or Ximeng Forestry Bureau. No specific permits were required for the described field studies involving the investigations of seed setting from the studied bamboo forest. The field studies did not involve endangered or protected plant or animal species.

\section{Consent for publication}

Not applicable.

\section{Competing interests}

The authors declare that they have no competing interests.

\section{Author details}

${ }^{1}$ Research Institute of Resources Insects, Chinese Academy of Forestry, Bailongsi, Panlong District, Kunming 650233, China. ${ }^{2}$ Lushan Botanical Garden, Jiangxi Province and Chinese Academy of Sciences, Guling, Lushan District, Jiujiang 332900, China.

\section{Received: 15 April 2019 Accepted: 10 September 2019} Published online: 11 October 2019

\section{References}

1. Barrett SCH. The evolution of plant sexual diversity. Nat Rev Gen. 2002;3:274-84.

2. He YP, Liu JQ. A review of recent advances in the studies of plant breeding system. Acta Phytoecol Sin. 2003;27(2):151-63.

3. Vogler DW, Kalisz S. Sex among the flowers: the distribution of plant mating systems. Evolution. 2001;55(1):202-4.

4. Xie P. Scaling ecology to understand natural design of life systems and their operations and evolutions--integration of eoclogy, genetics and evolution through reproduction. Beijing: Science Press; 2013. p. 257-66.

5. Ritland K. Extensions of models for the estimation of mating systems using independent loci. Heredity. 2002;88(4):221-8.

6. Aldrich P, Hamrick JL. Reproductive dominance of pasture trees in a fragmented tropical forest mosaic. Science. 1998;281:103-5.

7. Li DZ, Wang ZP, Zhu ZD. Bambuseae. In: Wu ZY, Raven PH, Hong DY, editors. Flora of China, Beijing: science press; St. Louis: Missouri Botanic Garden Press; 2006. p. 25-48.

8. Yi TP, Shi JY, Ma LS, Wang HT, Yang L. Iconographia Bambusoidearum Sinicarum. Beijing: Science Press; 2008. p. 30-44.

9. Jiang $\mathrm{ZH}$. Bamboo and rattan in the world. Shenyang: Liaoning Science and Technology Publishing House; 2002. p. 50-86.

10. Sun MS, Yan B, Xu T, Yu LX. Resources and utilization of bamboo plants. Beijing: Science Press; 2015. p. 1-36.

11. Janzen $\mathrm{DH}$. Why bamboos wait so long to flower? Ann Rev Ecol Syst. 1976;7:347-91.

12. Ma PF, Vorontsova MS, Nanjarisoa OP, Razanatsoa J, Guo ZH, Haevermans T, Li DZ. Negative correlation between rates of molecular evolution and flowering cycles in temperate woody bamboos revealed by plastid phylogenomics. BMC Plant Biol. 2017;17:260.

13. Zhang YT, Tang DQ, Lin XC, Ding MQ, Tong ZK. Genome-wide identification of MADS-box family genes in moso bamboo (Phyllostachys edulis) and a functional analysis of PeMADS5 in flowering. BMC Plant Biol. 2018;18:176.

14. Xiao GH, Li BJ, Chen HJ, Chen W, Wang ZY, Mao BZ, Gui RY, Guo XQ. Overexpression of PvCO1, a bamboo CONSTANS-LIKE gene, delays flowering by reducing expression of the FT gene in transgenic Arabidopsis. BMC Plant Biol. 2018;18:232.

15. Du F, Xue JR, Yang MY, Hui CM, Wang J. Study on flowering phenomenon and its type of bamboo in Yunnan in past fifteen years. Sci Silv Sin. 2000;36(6):51-68.

16. Chen LN, Cui YZ, Wong KM, Li DZ, Yang HQ. Breeding system and pollination of two closely related bamboo species. Aob Plants. 2017;9(3):plx021.

17. Nadgauda RS, John CK, Mascarenhas AF. Floral biology and breeding behavior in the bamboo Dendrocalamus strictus Nees. Tree Physiol. 1993;13:40|-8.
18. Zhong YB, Yue JJ, Lou C, Yuan JL, Gu XP. Floral organ and breeding system of Dendrocalamus latiflorus. Sci Silv Sin. 2017;53:1):1-10.

19. Kitamura K, Kawahara T. Estimation of outcrossing rates at small-scale flowering sites of the dwarf bamboo species, Sasa cernua. J Plant Res. 2011;124(6):683-8

20. Matsuo A, Tomimatsu H, Suzuki Jl, Saitoh T, Shibata S, Makita A, Suyama Y. Female and male fitness consequences of clonal growth in a dwarf bamboo population with a high degree of clonal intermingling. Ann Bot. 2014;114:1035-41.

21. Liu ZJ, Lin Y, Zhou MB, Tang DQ. Estimation of outcrossing rate in Phyllostachys edulis by microsatellite polymorphism. Sci Silv Sin. 2014;50(8):76-81.

22. Gu ZJ, Yang HQ, Sun MS, Yang YM. Distribution characteristics, flowering and seeding of Dendrocalamus sinicus in Yunnan, China. Forest Res. 2012;25:1):1-5.

23. Xie N, Chen LN, Wong KM, Cui YZ, Yang HQ. Seed set and natural regeneration of Dendrocalamus membranaceus Munro after mass and sporadic flowering in Yunnan, China. PLoS One. 2016;11(4):e0153845.

24. Yang HQ, An MY, Gu ZJ, Tian B. Genetic diversity and differentiation of Dendrocalamus membranaceus (Poaceae: Bambusoideae), a declining bamboo species in Yunnan, China, as based on inter-simple sequence repeat (ISSR) analysis. Int J Mol Sci. 2012;13(4):4446-57.

25. Jones OR, Wang J. COLONY: a program for parentage and sibship inference from multilocus genotype data. Mol Ecol Res. 2010;10:551-5.

26. Duminil J, Abessolo DTM, Bourobou DN, Doucet JL, Loo J, Hardy OJ. High selfing rate, limited pollen dispersal and inbreeding depression in the emblematic African rain forest tree Baillonella toxisperma - management implications. Forest Ecol Manag. 2016;379:20-9.

27. Mizuki I, Sato A, Matsuo A, Suyama Y, Suzuki J, Makita A. Clonal structure, seed set, and self-pollination rate in mass-flowering bamboo species during off-year flowering events. PLoS One. 2014;9(8):e105051.

28. Opedal $\varnothing \mathrm{H}$, Falahati-Anbaran M, Albertsen E, Armbruster WS, Pérez-Barrales R, Stenøien HK, Pélabon C. Euglossine bees mediate only limited longdistance gene flow in a tropical vine. New Phytol. 2017;213(4):1898-908.

29. Lasker HR, Gutiérrez-Rodríguez C, Bala K, Hannes A, Bilewitch JP. Male reproductive success during spawning events of the octocoral Pseudopterogorgia elisabethae. Marine Ecol Prog Series. 2008;367:153-61.

30. Harrison HBB, Williamson DHH, Evans RDD, Almany GR, Thorrold SR, Russ GR, Feldheim KA, Herwerden LV, Planes S, Srinivasan M, Berumen ML, Jones GP. Larval export from marine reserves and the recruitment benefit for fish and fisheries. Curr Biol. 2012;22:1023-8.

31. Warner PA, Willis BL, Madeleine JHO. Sperm dispersal distances estimated by parentage analysis in a brooding scleractinian coral. Mol Ecol. 2016;25(6):1398-415

32. Burczyk J, Adams WT, Shimizu JY. Mating patterns and pollen dispersal in a natural knobcone pine (Pinus attenuata Lemmon.) stand. Heredity. 1996;77:251-60.

33. Dow BD, Ashley MV. High levels of gene flow in bur oak revealed by paternity analysis using microsatellites. J Heredity. 1998;89:62-70.

34. Streiff R, Ducousso A, Lexer C, Steinkellner H, Gloessl J, Kremer A. Pollen dispersal inferred from paternity analysis in a mixed oak stand of Quercus robur L. and Q. petraea (Matt.) Liebl. Mol Ecol. 1999;8(5):831-41.

35. Bittencourt JVM, Sebbenn AM. Pollen movement within a continuous forest of wind-pollinated Araucaria angustifolia, inferred from paternity and TwoGener analysis. Conserv Genet. 2008;9:855-68.

36. Dong YR, Yang HQ. Development of seventeen novel microsatellite markers of a wild and flowering bamboo Dendrocalamus membranaceus (Poaceae) and cross-amplification in Dendrocalamus genus. Conserv Genet Res. 2014;6(1):201-3.

37. Dong YR, Zhang ZR, Yang HQ. Sixteen novel microsatellite markers developed for Dendrocalamus sinicus (Poaceae), the strongest woody bamboo in the world. Am J Bot. 2012;99(9):e347.

38. Zhang YJ, Ma PF, Li DZ. High-throughput sequencing of six bamboo chloroplast genomes: phylogenetic implications for temperate woody bamboos (poaceae: bambusoideae). PLoS One. 2011;6(5):e20596.

39. Gao ZM, Li CL, Peng ZH. Generation and analysis of expressed sequence tags from a normalized cDNA library of young leaf from Ma bamboo (Dendrocalamus latiflorus Munro). Plant Cell Rep. 2011;30(11):2045-57.

40. Yang HQ, Liang N, Li CF, Li TC, Sun MS. Seed germination and storage of six woody bamboo species in Yunnan, China. Forest Res. 2013;26(6):710-4.

41. Whitehead DR. Pollination biology. Cambridge: Academic Press; 1983. p. 97-108. 
42. Hahn CZ, Michalski SG, Durka W. Gene flow in, and mating system of Rhododendron simsii in a nature reserve in subtropical China. Nord Bot. 2016;35(1):1-7.

43. Asuka Y, Tomaru N, Munehara Y, Tani N, Tsumura Y, Yamamoto S. Half-sib family structure of Fagus crenata saplings in an old-growth beech-dwarf bamboo forest. Mol Ecol. 2005;14(8):2565-75.

44. Lasso E, Dalling JW, Bermingham E. Strong spatial genetic structure in five tropical piper species: should the baker-Fedorov hypothesis be revived for tropical shrubs? Ecol Evol. 2011;1(4):502-16.

45. Theim TJ, Shirk RY, Givnish TJ. Spatial genetic structure in four understory Psychotria species (Rubiaceae) and implications for tropical forest diversity. Am J Bot. 2014;101(7):1189-99.

46. Martén-Rodríguez S, Fenster CB. Pollen limitation and reproductive assurance in Antillean Gesnerieae: a specialists vs. generalist comparison. Ecology. 2010;91(1):155-65.

47. McClure FA. The bamboos, a fresh perspective. MA, USA: Harvard University Press; 1966. p. 1-106.

48. Doyle JJ, Doyle JL. A rapid DNA isolation procedure for small quantities of fresh leaf tissue. Phytochem Bull. 1987;19:11-5.

49. Harrison HB, Saenz-Agudelo P, Planes S, Jones GP, Berumen ML. Relative accuracy of three common methods of parentage analysis in natural populations. Mol Ecol. 2013:22:1158-70.

50. Smouse PE, Meagher TR. Genetic analysis of male reproductive contribution in Chamaelirium luteum (L.) gray (Liliaceae). Genetics. 1994;136(1):313-22.

51. Zhang DM, Shen XH, He TH. A paternity analysis of seeds from different closes in a Pinus tabulaeformis Carr. Seed orchard. Acta Phytoecol Sin. 2001;25(2):166-74.

\section{Publisher's Note}

Springer Nature remains neutral with regard to jurisdictional claims in published maps and institutional affiliations.

Ready to submit your research? Choose BMC and benefit from:

- fast, convenient online submission

- thorough peer review by experienced researchers in your field

- rapid publication on acceptance

- support for research data, including large and complex data types

- gold Open Access which fosters wider collaboration and increased citations

- maximum visibility for your research: over $100 \mathrm{M}$ website views per year

At BMC, research is always in progress.

Learn more biomedcentral.com/submissions 